\title{
0460 MOTIVATION TO ATTEND MOTORCYCLE TRAINING COURSE FOR BEGINNING RIDER
}

$\mathrm{N}$ Waiyanate*, P Aniwattakulchai, T Sigama Correspondence: Asian Institube of technology (AIT), P.O. Box 4, Klong 1, Klong Luang, Pathum Thani 12120, Thailand

\subsection{6/ip.2010.029215.460}

Introduction Motorcycle represents the highest number of vehicle in Thailand, the increasing of motorcycle registry cause effects to the number of accident injuries and death. The first two age groups of injuries are 20-29 and 10-19 years old. Statement of the problem from the previous research show experience in accident and injury rider who learnta skill practice by themselves and their friend are the most high risk group. A safety riding program can decrease $30 \%$ of injury, but only $0.03 \%$ of Thai riders has been learnt this course. How to increase number of riders passing a safety riding training course. The propose of survey and interview about learning process for riders license and evaluate attitude of beginning rider toward the licensing examination.

Method A self-reported survey rider who get in to a licensing process at land Transportation Authority Office (LTAO)and a safety riding school.

Results Altogether 246 (LTAO) rider and 84 (A-P Honda rider) Most of beginning riders start to practice riding when younger than 15 years old. Learning from parents and practice by themselves on road in neighbourhood, reason to test at (LTAO) not convenient to go to riding school, easy and simple to skill test and disagree with the law everybody need to attend a riding school. Rider from safety driving school agree that it is useful for riding skill improvement, training cost time period lecture and practice are suitable.

Recommendation Convince people that long time training can improve riding skill experience. 